\title{
Successful conservative surgical management of ovarian mucinous cystadenoma with silent torsion in pregnancy: a case report
}

\author{
Arpita De*, Reva Tripathi
}

Department of Obstetrics and Gynecology, Hamdard Institute of Medical Sciences and Research, New Delhi, India

Received: 19 December 2019

Revised: 18 January 2020

Accepted: 24 January 2020

\author{
*Correspondence: \\ Dr. Arpita De, \\ E-mail: arpitade07@gmail.com
}

Copyright: () the author(s), publisher and licensee Medip Academy. This is an open-access article distributed under the terms of the Creative Commons Attribution Non-Commercial License, which permits unrestricted non-commercial use, distribution, and reproduction in any medium, provided the original work is properly cited.

\begin{abstract}
To report the successful conservative surgical management of Ovarian mucinous cystadenoma with silent torsion in a 24 years old pregnant woman in a tertiary care center in Delhi. An antenatal woman came for a routine visit to the OPD of the hospital at 13 weeks gestation. She had a vague, mild pain in lower abdomen since the last four weeks. A cystic mass was discovered during an abdominal examination. Further on sonography, a multisepatated cystic mass was seen, likely to be mucinous cystadenoma. Routine tumor markers came out to be negative. A laparotomy was planned at 15 weeks. On laparotomy a $20 \times 15 \mathrm{~cm}$ multiloculated cyst with one and half turns of torsion was found. Detorsion, cystectomy of the intact cyst followed by ovarian reconstruction was done after due consent. On histopathological examination the cyst was found to be Benign mucinous cystadenoma. The pregnancy continued without any adverse effects. The woman delivered vaginally at 38 weeks without any feto-maternal complications. She was able to conceive again spontaneously at 18 months post-delivery. After 16 weeks of gestation in the second pregnancy she went to her home town and no further follow-up was possible. This case emphasizes the importance of a thorough examination in all pregnant woman to rule out any adnexal mass separate from the gravid uterus. Big ovarian masses in pregnancy, if not diagnosed can cause growth retardation, preterm deliveries, acute abdomen due to infection, rupture or torsion. Sonography, MRI and tumor markers can facilitate diagnosis before surgery. Torsion and rupture of mucinous cystadenoma need prompt surgery. Wherever possible conservative surgery (detorsion and cystectomy) should be done especially in young women.
\end{abstract}

Keywords: Adnexal mass in pregnancy, Mucinous cystadenoma in pregnancy, Silent torsion in pregnancy

\section{INTRODUCTION}

Mucinous tumors account for around $15 \%$ of ovarian tumors. ${ }^{1}$ Big ovarian tumors coexisting with pregnancy can predispose to complications like preterm labour, growth retardation, PPROM and acute abdomen due to torsion, infection or rupture. These can compromise the obstetric outcomes. $^{2}$ This is the case of a pregnant woman who was diagnosed with a $20 \mathrm{~cm}$ ovarian mass in her routine antenatal visit at 13 weeks. It was operated at 15 weeks. A mucinous cystadenoma with torsion was found.
Detorsion, ovarian cystectomy with reconstruction was done. The pregnancy continued without complications and she delivered vaginally at term. This case highlights the importance of correct diagnosis, timely surgery and the necessity to perform an ovarian cystectomy with reconstruction wherever possible.

\section{CASE REPORT}

A 24-year-old primigravida woman presented to the antenatal OPD for a routine checkup at 13 weeks. On 
complete history it was revealed that she had occasional pain in the pelvis from few weeks after conceiving. It was mild, self-limiting and localized to the pelvis. It had slightly increased in intensity in the last one month, but she did not need any medications for the same. There was no excessive vomiting. She had noticed an abdominal bulge which she assumed to be the growing uterus. On examination an epigastric bulge was seen separate from the bulge of the gravid uterus (Figure 1). On palpation a mobile, nontender and central soft cystic mass was seen to occupy the whole abdomen corresponding to 30 weeks size. On sonography multiple large multiloculated cystic lesions were seen in the pelvis, extending upto upper abdomen, arising from bilateral adnexa with low level internal echoes, largest of $13 \times 10.3 \times 13.8 \mathrm{~cm}$ (vol$900 \mathrm{cc}$ ) were seen. Her Ca-125 was normal. Looking at the clinical and radiological profile a provisional diagnosis of mucinous cystadenoma was made. MRI was advised but couldnot be afforded by the family.

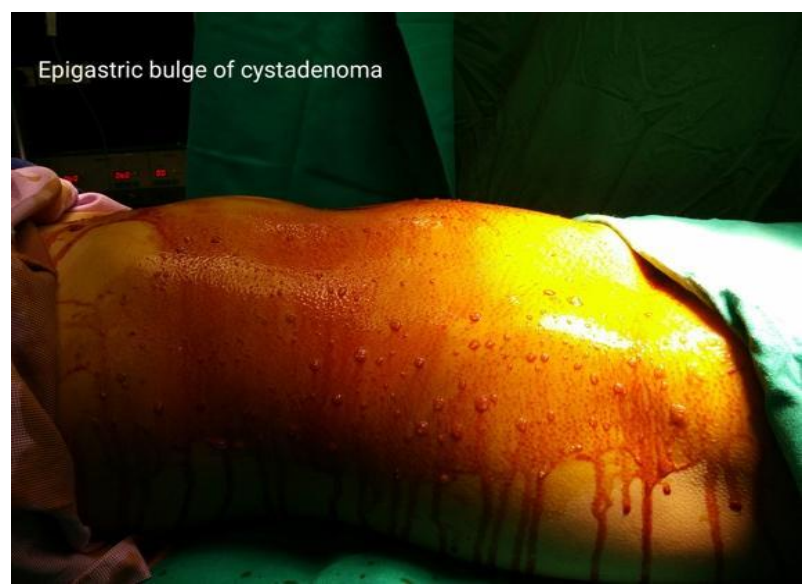

Figure 1: Preoperative epigastric bulge of ovarian mass sitting over the gravid uterus.

A laparotomy was planned at 15 weeks. A progesterone depot injection was given. A paraumbilical vertical incision was given. Minimal peritoneal fluid was present, same was sent for cytology. A smooth multilocular cyst, with mild congestion and moderately engorged vessels was seen to arising from the left ovary, with a size of around $25 \times 15 \mathrm{~cm}$, extending into the right pelvis. The cyst was resting on the growing uterus and was found to have one and half turns of torsion. The right tube, ovary and the left tube were normal. Consent was taken for cystectomy and was counselled about the possible need to re-operate after getting the final histopathology report. To enable intact delivery of the tense cyst outside the body, a controlled aspiration of one of the locules was done outside the peritoneal cavity ensuring that no spill occurred. The cyst contained mucinous fluid. Detorsion followed by a cystectomy and ovarian reconstruction was done (Figure 2 - 4). The gravid uterus was not touched. The inner portion of the cyst had no solid or hemorrhagic areas. The postoperative period was uneventful and she was discharged on the fifth day of surgery on micronized progesterone alone.

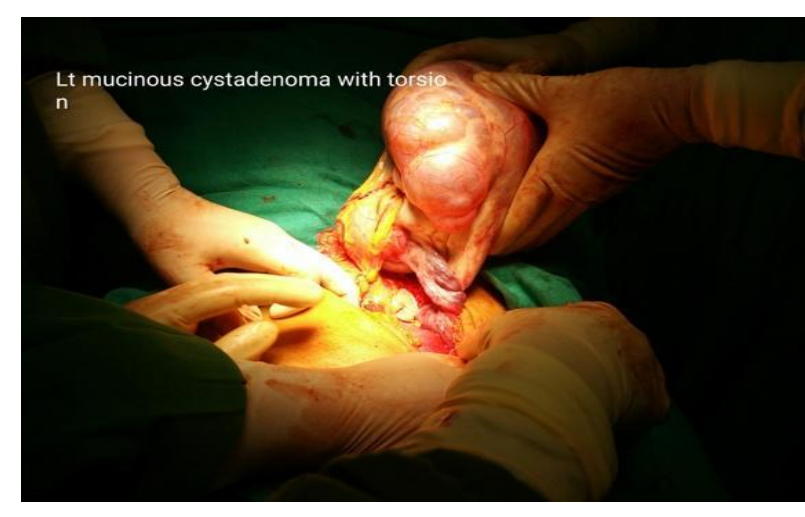

Figure 2: Multiloculated mucous cystadenoma with torsion.

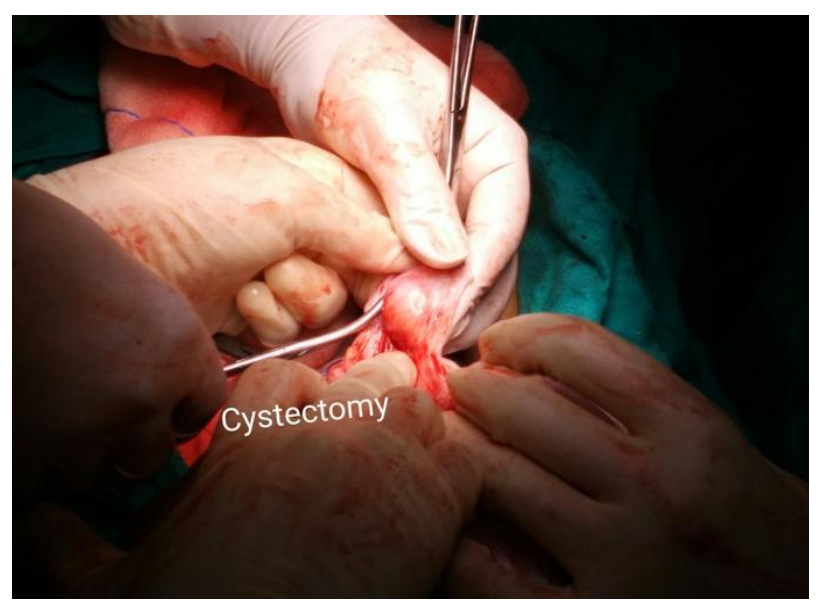

Figure 3: Cystectomy with thinned out cortex.

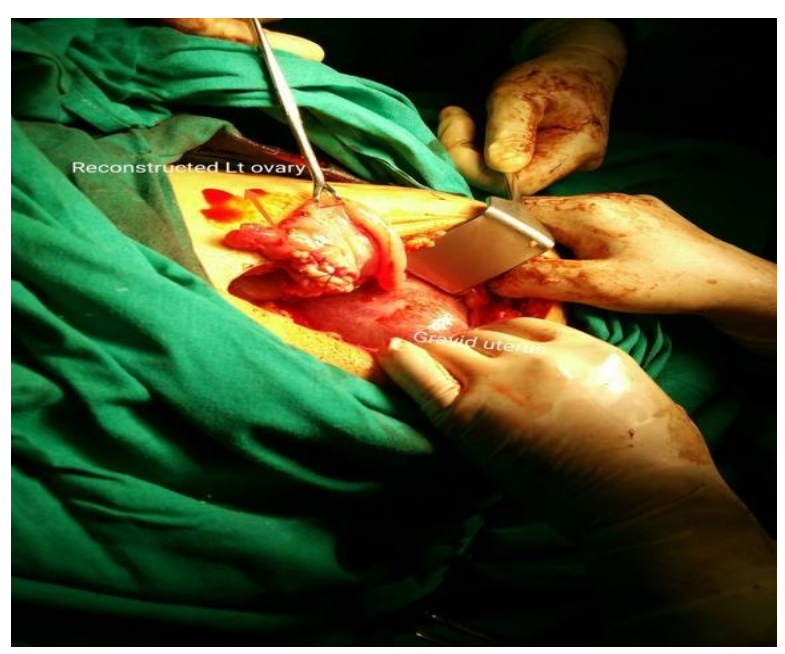

Figure 4: Reconstructed ovary.

Histopathological examination confirmed benign mucinous cystadenoma. Cytology revealed no malignant cells.

She was followed up regularly. She delivered vaginally at 38 weeks. Postnatal period was uneventful. She conceived spontaneously again after 18 months and was 
followed up till 16 weeks of the second pregnancy. Further follow up was not possible as she moved to her home town.

\section{DISCUSSION}

Mucinous cystadenoma is a benign ovarian tumour arising from the surface epithelium of the ovary, usually found in middle aged women. It is uncommon in adolescence and in pregnancy. ${ }^{2-4}$ Eighty percent of mucinous tumors are benign, $10 \%$ are malignant and $10 \%$ are borderline. ${ }^{5}$ Ten percent of these are bilateral. ${ }^{3}$ On gross examination mucinous cystadenomas are of variable sizes and usually have smooth inner and outer surfaces. They may be multilocular and tend to be huge in size. ${ }^{6}$ As the name suggests they have glycoprotein rich mucinous fluid within.

The most common benign adnexal masses during pregnancy are cystic teratomas (36\%), followed by cystadenomas (15\%)..$^{3,5,7,8}$ Torsion can occur in $5 \%$ of benign cysts in pregnancy, mostly in the first trimester and the puerperium. In this case a silent torsion had occurred between the time of diagnosis at 13 weeks and the scheduled surgery at 15 weeks. This has to be kept in mind as rupture of mucinous cystadenoma can lead to deposits of mucin in the peritoneum leading to Pseudomyxoma peritoneii. ${ }^{2}$

Adnexal masses less than $5 \mathrm{~cm}$ are unlikely to cause any symptoms. Therefore, the size of the tumor, its ultrasound characteristics, color Doppler flow, and symptoms are important in determining the management of pregnant patients with adnexal masses. Symptomatic, solid, bilateral, and complex lesions should be subjected to surgery whenever discovered. MRI is an useful and safe imaging modality for correct evaluation of adnexal masses in pregnancy. ${ }^{9}$ Unilateral simple ovarian cysts, 5$8 \mathrm{~cm}$ in size, should be evaluated sonologically up to $16-$ 18 weeks and if they fail to regress or if they increase in size, surgical intervention should be undertaken. It is also advisable that any surgical intervention in the first trimester be avoided if possible, because of the high rate of spontaneous abortion. The optimum time for surgical intervention is 16-18 weeks of gestation. Wherever possible a cystectomy should be done in young women. ${ }^{3}$

Several cases of ovarian mucinous cystadenomas have been reported in pregnancies. Some have showed features of maternal virilization and fetal growth restriction. Fetal growth restriction may be either due to the prominent vascularity of the tumor, originating from the ovarian vessels, or due to the compressive effect of the tumor on the uterine blood supply. $5,7,8,10,11$

In some studies huge mucinous cysadenomas have been removed at the time of diagnosis and the women have delivered vaginally successfully at term. ${ }^{10}$ In other studies when they have been diagnosed late, either the huge cystadenoma was removed by a laparotomy after a week of vaginal delivery or they have been removed after cesarean sections at term. $5,7,12,13$

\section{CONCLUSION}

More and more number of ovarian cysts are being diagnosed with sonography in the first trimester. Silent torsion can occur and should be looked for, as in this case. Doppler and MRI are a safe and useful modality to aid diagnosis. Acute complications will require emergency surgeries. Any mass which is complex or more than $7 \mathrm{~cm}$ should be operated, preferably in the second trimester. In case the mass is diagnosed near term, both vaginal and cesarean delivery may be considered. A thorough evaluation and management of the ovarian mass can be done with the cesarean or a week after a vaginal delivery.

\section{Funding: No funding sources \\ Conflict of interest: None declared \\ Ethical approval: Not required}

\section{REFERENCES}

1. Mittal S, Gupta N, Sharma A, Dadhwal V. Laparoscopic management of a large recurrent benign mucinous cystadenoma of the ovary. Arch Gynecol Obstet. 2008;277(4):379-80.

2. Nimbalkar AH. Successful pregnancy in voluminous ovarian mucinous cystadenoma. J Evid Based Med Healthcare. 2015;2(9):1355-8.

3. Alobaid AS. Mucinous cystadenoma of the ovary in a 12-year-old girl. Saudi Med J. 2008;29(1):126-8.

4. Ozgun MT, Turkyilmaz C. A giant ovarian mucinous cystadenoma in anadolescent: a case report. Arch Med Sci. 2009;5(2):281-3.

5. IJMS Yenicesu GI, Cetin M, Arici S. A huge ovarian mucinous cystadenoma complicating pregnancy: a case report. Cumhuriyet Med J. 2009;31:174-7.

6. Kamel. A massive ovarian mucinous cystadenoma: a case report. Reprod Biol Endocrinol. 2010;8:24.

7. Qublan HS, Al-Ghoweri AS, Al-Kaisi NS, AbuKhait SA. Benign mucinous cystadenoma with stromal luteinization during pregnancy: a hormonally responsive tumor and a rare cause of fetal intrauterine growth restriction. J Obstet Gynaecol Res. 2002;28:104-7.

8. Balat O, Kutlar I, Erkiliç S, Sirikçi A, Aksoy F, Aydin A. Unthreatened late pregnancy with a huge mucinous cyst adenoma of the left ovary: report of an unusual case. Eur J Gynaecol Oncol. 2002;23:84.

9. De Haan J, Verheecke M, Amant F. Management of ovarian cysts and cancer in pregnancy. Facts Views Vis Obgyn. 2015;7(1):25-31.

10. Noreen H, Syed S, Chaudhri R, Kahloon LE. A large unilocular mucinous cystadenoma in third trimester of pregnancy. J Coll Physicians Surg Pak. 2011;21:426-8.

11. Bolat F, Parlakgumus A, Canpolat T, Tuncer I. Benign mucinous cystadenoma with stromal 
luteinization responsible for maternal virilization and fetal intrauterine growth restriction. J Obstet Gynaecol Res. 2011;37:893-6.

12. Mandi D, Mondal RC, Debasish B, Maity AK, Nandi MK, Singh K. Successful vaginal delivery despite a huge ovarian mucinous cystadenoma complicating pregnancy: a case report. Iran J Med Sci. 2013;38:4.

13. Mandi D, Mondal RCh, Bhar D, Maity AK, Nandi MK, Singh K. Successful Vaginal delivery despite a huge ovarian mucinous cystadenoma complicating pregnancy: a case report. IJMS. 2013;38(4):339-42.

Cite this article as: De A, Tripathi R. Successful conservative surgical management of ovarian mucinous cystadenoma with silent torsion in pregnancy: a case report. Int J Reprod Contracept Obstet Gynecol 2020;9:1278-81. 